\title{
Wound fluid enhances cancer cell proliferation via activation of STAT3 signal pathway in vitro
}

\author{
AGMAL SCHERZAD $^{1}$, THOMAS GEHRKE ${ }^{1}$, TILL MEYER $^{1}$, PASCAL ICKRATH $^{1}$, \\ MAXIMILIAN BREGENZER ${ }^{1}$, RAFAEL EITER ${ }^{1}$, RUDOLF HAGEN ${ }^{1}$, \\ NORBERT KLEINSASSER ${ }^{2}$ and STEPHAN HACKENBERG ${ }^{1}$
}

\author{
${ }^{1}$ Department of Otorhinolaryngology, Plastic, Aesthetic and Reconstructive Head and Neck Surgery, \\ Julius Maximilian University of Wuerzburg, 97080 Würzburg, Germany; \\ ${ }^{2}$ Department of Otorhinolaryngology, Kepler University, 4020 Linz, Austria
}

Received March 13, 2018; Accepted January 24, 2019

DOI: $10.3892 /$ or.2019.7047

\begin{abstract}
Wound healing begins immediately after surgery with a modification of the microenvironment via a well-orchestrated interaction between cells, cytokines and growth factors. Some of these growth factors and cytokines have mitogenic effects on cancer cells, which may lead to enhanced cancer cell proliferation and early metastatic events. The present study aimed to investigate the effects of wound fluid (WF) on the head and neck squamous carcinoma cell lines FaDu and HLaC78 in vitro. WF was harvested from 7 patients who had undergone a planned neck dissection. The presence of cytokines and growth factors was evaluated with the dot blot assay. Proliferation and cell viability were investigated via MTT assay and Ki-67 staining. Cell invasion was measured via tree-dimensional invasion assay. Western blotting was used to investigate STAT 3 activation. WF contained several cytokines and growth factors responsible for pro- and anti-inflammation, chemotaxis, proliferation and angiogenesis. The proliferation effect of WF on FaDu and HLaC78 was concentration dependent. Media with 40\% WF resulted in the highest proliferation effect. $\mathrm{FaDu}$ and $\mathrm{HLaC} 78$ exhibited enhanced motility after cultivation with $40 \%$ WF compared with cultivation with expansion medium. Cultivating cancer cells with WF had no advantageous effect on cell viability after the paclitaxel treatment. Western blot analysis revealed enhanced activation of the STAT3 signaling pathway by WF in both FaDu and HLaC78. In conclusion, surgery leads to excessive release of mitogenic factors. The contact of non-resected cancer cells and these factors may have a negative impact on patient outcome. Future
\end{abstract}

Correspondence to: $\mathrm{Dr}$ Agmal Scherzad, Department of Otorhinolaryngology Plastic, Aesthetic and Reconstructive Head and Neck Surgery, Julius Maximilian University of Wuerzburg, 11 Josef-Schneider Street, 97080 Würzburg, Germany

E-mail: Scherzad_A@ukw.de

Key words: wound fluid, head and neck cancer, cytokines, cancer proliferation investigations should specifically focus on the inhibition of mitogenic factors following cancer surgery in order to prevent early metastasis and cancer recurrence.

\section{Introduction}

In 2017, 1,688,780 new cancer cases and 600,920 cancer deaths were projected to occur in the US (1). Therapy varies depending on the type of cancer, origin and localization. Surgery is one major option for treating malignant disease. After surgery, wound healing commences immediately. During this process, a complex inflammatory response is triggered, which induces the recruitment, proliferation and activation of cells such as neutrophils, macrophages, natural killer cells, fibroblasts and mesenchymal stem cells $(2,3)$. The process of wound healing is orchestrated via the interaction between different cells, cytokines, and the extracellular matrix. Surgical wound fluid (WF) contains blood cells, immune cells, lymph and paracrine-released factors (4). The composition of factors and cell components in WF differ in a time-dependent manner, and there are ample interindividual differences (5). From an oncological point of view, the mechanisms of wound healing are quite interesting, as non-resected cancer cells may be exposed to mitogenic factors in the wound microenvironment after surgical cancer therapy (6). In a previous study, the presence of a variety of different cytokine and growth factors in the WF of patients who underwent a planned neck dissection was demonstrated (7). The cultivation of mesenchymal stem cells (MSCs) with WF induced enhancement of cell proliferation and cell migration. Most of the cytokines contained in WF are known to be pro-tumorigenic, for example, interleukin (IL)-6. IL-6 is a pleiotrophic cytokine, which is secreted by cells from the immune system or fibroblasts. Cancer cells, for example, from the breast, lung, or prostate also secrete IL-6 (8). Furthermore, IL-6 is an important pro-inflammatory cytokine and a mediator of the immune system, and it stimulates the differentiation of B-cells. Conversely, IL-6 serves an important role in cancer biology by inducing tumor growth via the activation of Ras/Raf/MEK/extracellular signal-regulated kinase $1 / 2(9,10)$. Increased serum levels of IL-6 seem to be associated with severity of disease and poor outcome (11). 
Suchi et al (12) demonstrated a suppressed cisplatin-induced cytotoxicity in esophageal cancer cells via overexpression of IL-6. Additionally, IL-6 has been linked to enhanced cancer cell migration and metastasis (13).

In the process of cancer progression, the activation of signal transducers and activators of transcription (STAT) 3 is important. STAT3 transcription factors are activated by cytokines, growth factors, and hormones (14). The activation of STAT3 is achieved by phosphorylation of its tyrosine and serine residues (15). STAT3 is activated particularly by IL-6 family cytokines, which includes IL-6, IL-8, IL-11 and Oncostatin (16). Cancer cells and cancer surrounding stroma are able to activate STAT3 via autocrine and paracrine production of IL-6 family cytokines (17).

The aim of the present study was to investigate the effects of WF on the head and neck squamous carcinoma cell lines $\mathrm{FaDu}$ and $\mathrm{HLaC} 78$ in terms of cell viability, proliferation, migration and induction of chemoresistance. Furthermore, the cytokine pattern of WF and possible activation of the STAT3 signaling pathway were also investigated.

\section{Materials and methods}

Culture of human carcinoma cell lines FaDu and HLaC78. The head and neck squamous carcinoma cell lines FaDu and HLaC78 were used $(18,19)$. Cells were grown in RPMI-1640 medium (Biochrom, Ltd., Cambridge, UK) with $10 \%$ fetal calf serum (FCS) (Linaris Blue Wertheim-Bettingen, Germany), $100 \mathrm{U} / \mathrm{ml}$ penicillin, $100 \mu \mathrm{g} / \mathrm{ml}$ streptomycin, $1 \%$ sodium pyruvate $(100 \mathrm{mM}$; Biochrom, Ltd.), and $1 \%$ non-essential amino acids [100-fold concentration; Biochrom AG; RPMI-expansion medium (RPMI-EM)]. Cells were cultured in flasks at $37^{\circ} \mathrm{C}$ with $5 \% \mathrm{CO}_{2}$. The replacement of the medium was carried out every other day, and passaging was performed after reaching 70-80\% confluence by trypsinization ( $0.25 \%$ trypsin; Gibco; Thermo Fisher Scientific, Inc., Waltham, MA, USA). Experiments were performed using cells in the exponential growth phase.

Collection of WF. The WF of 7 male patients (age, 51-88 years; the exclusion criteria was prior administration of radiation therapy) who underwent a planned neck dissection at the Department of Otorhinolaryngology, Plastic, Aesthetic and Reconstructive Head and Neck Surgery at Julius Maximilian University of Wuerzburg (Würzburg, Germany), was collected in 2009 and 2017 from a vacuum drain $72 \mathrm{~h}$ after surgery. Written, informed consent was provided by all patients. The study was approved by the Ethics Committee of the Medical Faculty of the University of Wuerzburg. After harvesting WF, centrifugation at $340 \mathrm{x} \mathrm{g}$ for $10 \mathrm{~min}$ at $4^{\circ} \mathrm{C}$ was conducted immediately in order to reduce cell debris. To remove immune cells, a second centrifugation at $340 \mathrm{x}$ g for $10 \mathrm{~min}$ at $4^{\circ} \mathrm{C}$ in Leucosep medium (GE Healthcare, Chicago, IL, USA) followed. Next, the WF was filtered using a $0.45-\mu \mathrm{m}$ syringe filter (Sarstedt, Inc., Newton, NC, USA). To avoid bacterial infection, $100 \mathrm{U} / \mathrm{ml}$ penicillin and $100 \mathrm{mg} / \mathrm{ml}$ streptomycin (1\% penicillin/streptomycin) were added.

Cytokine analysis of WF. The cytokine pattern of WF was detected with the dot blot assay. All reagents and materials used, including the C-Series Human Cytokine Antibody Array 3 kit (cat. no. AAH-CyT-3-4) were supplied by RayBiotech Inc. (Norcross, GA, USA). The supplier provided all supplements. After harvesting WF, the presence of cytokines was investigated according to the manufacturer's protocol. First, the WF was added to the membrane for $30 \mathrm{~min}$ at room temperature. After several washing steps, incubation for $2 \mathrm{~h}$ at room temperature with $1 \mathrm{ml}$ biotin-conjugated antibodies (prefabricated solution) and horseradish peroxidase (HRP)-conjugated streptavidin $(1: 1,000)$ was conducted. The labeled proteins were detected via chemiluminescence using detection buffer and exposure to X-ray film. The cytokines were represented as dots with different intensities and diameters. The quantification of the different cytokines was achieved by densitometric methods using ImageJ software (version 1.43u; National Institutes of Health, Bethesda, MD, USA).

Cell viability analysis. The mitochondrial activity of $\mathrm{HLaC} 78$ and $\mathrm{FaDu}$ cultivated with WF at different concentrations was investigated via MTT assay (Sigma-Aldrich; Merck KGaA, Darmstadt, Germany) as described previously (20). FCS was not added to the medium containing WF. First, cells were seeded at a density of $1 \times 10^{4}$ cells/well in a 96-well round bottom plate. The cultivation medium consisted of RPMI containing WF at various concentrations $(10,20,30,40,50,60,70,80,90$ and $100 \%$ ). Cells were cultivated for $24 \mathrm{~h}$. After a washing step with PBS, all plates were incubated with $100 \mu \mathrm{l}$ MTT solution $(1 \mathrm{mg} / \mathrm{ml})$ for $5 \mathrm{~h}$ at $37^{\circ} \mathrm{C}$. The MTT solution was removed and $100 \mu \mathrm{l}$ isopropanol was added for a further $1 \mathrm{~h}$ at $37^{\circ} \mathrm{C}$. The multi-plate reader (Titertek Multiskan PLUS MK II; Thermo Labsystems, Helsinki, Finland) was used to measure the color conversion at a wavelength of $570 \mathrm{~nm}$. Further experiments were conducted with WF at a concentration of $40 \%$.

The enhanced proliferation activity of cancer cells after cultivation with $40 \%$ WF was confirmed through Ki-67 staining. First, the cells were plated on specimen slides. After cultivation with WF for $48 \mathrm{~h}$, fixation was performed using $4 \%$ paraformaldehyde in PBS at $4^{\circ} \mathrm{C}$ for $30 \mathrm{~min}$. Then, a further 5 min of fixation with $100 \%$ acetone at room temperature was performed. Next, cells were incubated with $10 \%$ bovine serum albumin (BSA; Carl Roth GmbH and Co., KG, Karlsruhe, Germany) in Tris-buffered saline [200 mM Tris-base, $\mathrm{pH}$ 8; $8 \% \mathrm{NaCl}$; and $1 \%$ Tween-20 (TBS-T); Sigma-Aldrich; Merck KGaA). Incubation at $4^{\circ} \mathrm{C}$ of cells in TBS-T containing $1 \%$ BSA and a rabbit polyclonal antibody against Ki-67 (1:500; Abcam, Cambridge, UK; cat. no. Ab15580) was assessed overnight. After 3 washing steps with TBS-T, the cells were treated for $1 \mathrm{~h}$ in $1 \% \mathrm{BSA}$ at room temperature with Alexa 555-conjugted goat anti-rabbit secondary antibody (1:500; Invitrogen; Thermo Fisher Scientific, Inc.; cat. no. A21428) and $5 \mathrm{mg} / \mathrm{ml}$ DAPI (Sigma-Aldrich; Merck KGaA). Cancer cell lines cultivated in RPMI-EM served as a control. A fluorescence microscope (Leica DMI 4000B Inverted Microscope; Leica Microsystems $\mathrm{GmbH}$, Wetzlar, Germany) was used for cell examination at x100 magnification.

Paclitaxel treatment. In order to evaluate whether WF induces resistance toward chemotherapeutics, cells were cultivated in $40 \% \mathrm{WF}$ and treated with $10 \mathrm{nM}$ paclitaxel (University of Wuerzburg) for $24 \mathrm{~h}$ at $37^{\circ} \mathrm{C}$. Previously, half maximal inhibitory concentration $\left(\mathrm{IC}_{50}\right)$ was calculated (21). The MTT assay 

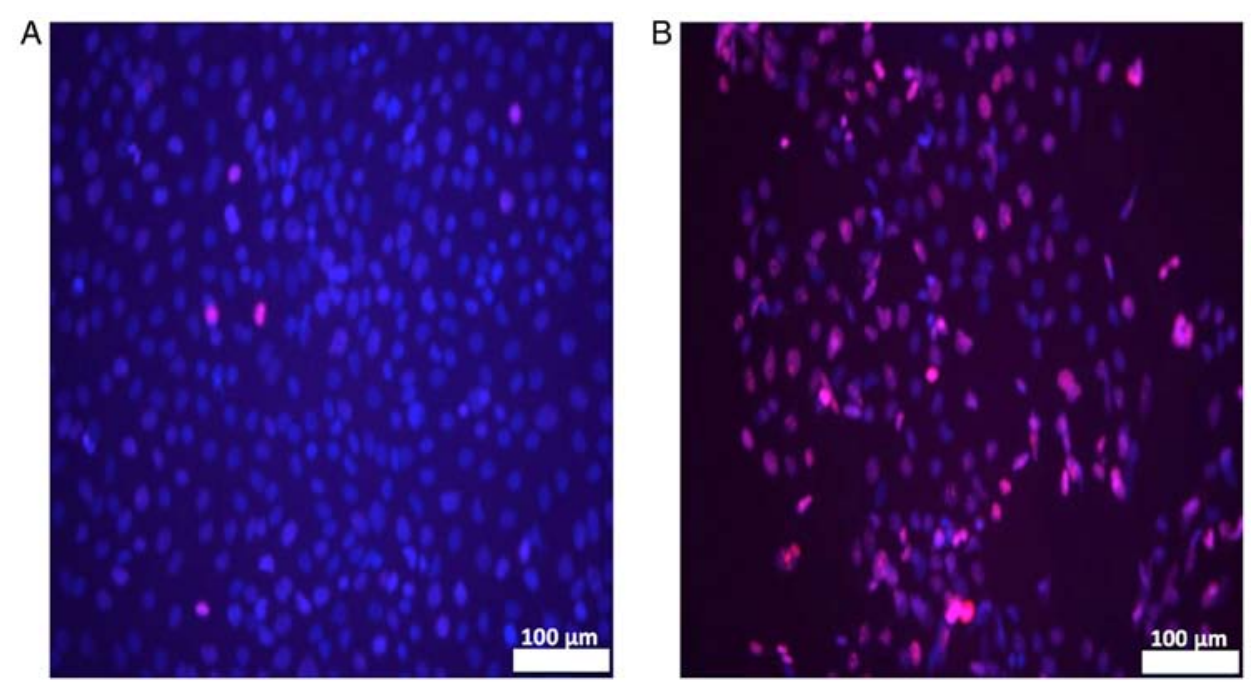

Figure 1. Ki-67 staining of FaDu. FaDu cells were cultured with (A) RPMI-EM and (B) 40\% WF. After 48 h, Ki-67 staining was performed. The cell nuclei were stained with DAPI. Cell proliferation was significantly enhanced following cultivation with 40\% WF compared with RPMI-EM. RPMI-EM, RPMI-expansion medium; WF, wound fluid.
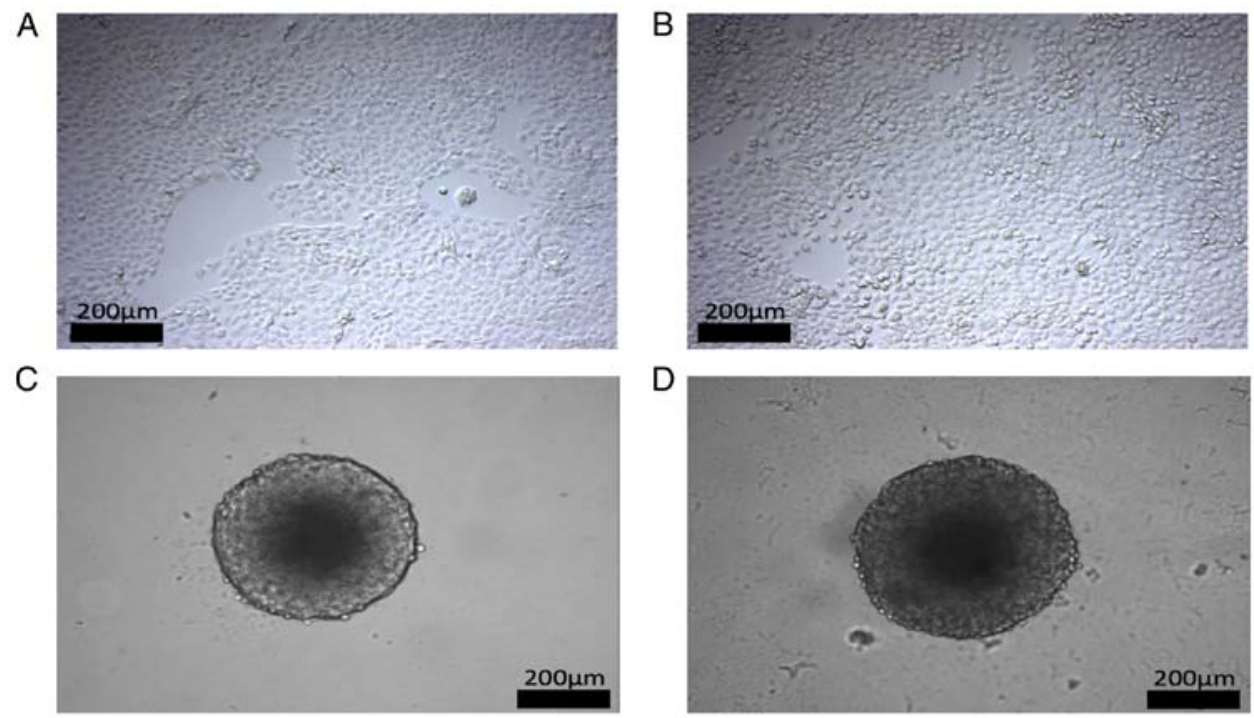

Figure 2. Microscopic analysis of cancer cells. Microscopic analysis of (A) FaDu and (B) HLaC78 in monolayer and (C) FaDu and (D) HLaC78 in spheroid assay with $40 \%$ wound fluid was conducted.

was used to determine cell viability as described above. Cancer cells cultivated with RPMI-EM and treated with paclitaxel served as a control.

Three-dimensional invasion assay. A possible alteration in the cell invasion activity was investigated using the three-dimensional invasion assay. First, a 96-multiwell plate was coated with $0.1 \%$ agar (Sigma-Aldrich; Merck KGaA). Next, spheroids were generated from $6 \times 10^{3}$ cells (FaDu or HLaC78). After $72 \mathrm{~h}$, spheroids were transferred to well plates coated with extracellular matrix (1:80; Sigma-Aldrich; Merck KGaA). The cells were able to spread out from the spheroids in the well plate. To determine the migration area, the cells were imaged directly after being transferred and after $24 \mathrm{~h}$ of culture using an inverted microscope (magnification, x50; Leica Microsystems $\mathrm{GmbH}$ ). The migration area was calculated using ImageJ software (version 1.43u).
Analysis of STAT3 activation via western blotting. Western blotting was performed as previously described (22). Cells (FaDu and HLaC78) were harvested by trypsinization and dissolved in radioimmunoprecipitation assay buffer (PBS containing $1 \%$ NP40, $0.5 \%$ sodium deoxycholate, and $0.1 \%$ SDS); then were supplemented with $10 \mu \mathrm{g} / \mathrm{ml}$ phenylmethanesulfonyl fluoride (PMSF). Protein concentration was then determined according to the method detailed previously by Lowry et al (23).

Equal amounts $(20 \mu \mathrm{g} / \mathrm{lane})$ of total protein lysates were loaded onto $10 \%$ SDS-PAGE and transferred by electroblotting to a polyvinylidene difluoride membrane. The blots were blocked for $1 \mathrm{~h}$ at room temperature with TBS-T $(10 \mathrm{mM}$ Tris, $150 \mathrm{mM} \mathrm{NaCl}, 0.05 \%$ Tween-20, $\mathrm{pH}$ 8.0) containing 5\% non-fat dry milk. Subsequently, the membrane was incubated with primary antibody against STAT3 (1:500; Cell Signaling Technology, Inc., Danvers, MA, USA; cat. 9145) overnight 

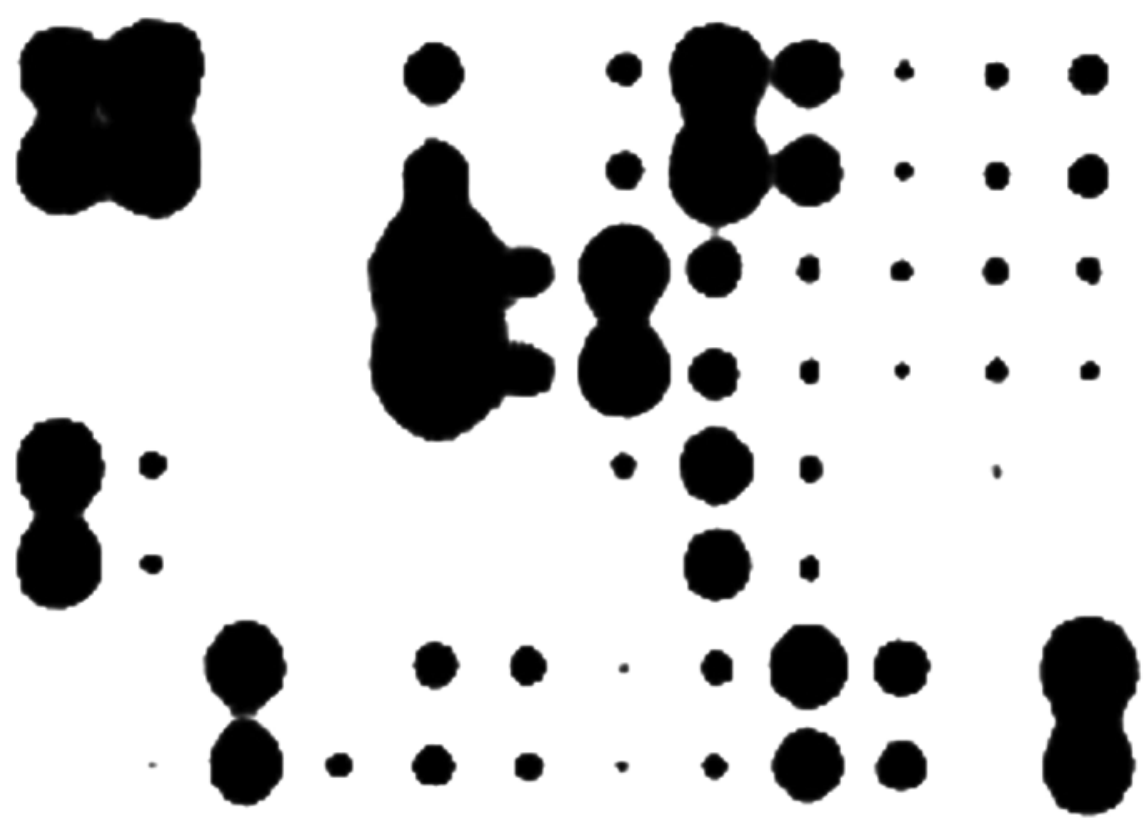

\begin{tabular}{|c|c|c|c|c|c|c|c|c|c|c|c|}
\hline+ & + & $=$ & - & ENA-78 & GCSF & GM-CSF & GRO & GRO-a & $1-309$ & IL-1a & IL-1 $\beta$ \\
\hline+ & $\overline{+}$ & - & - & ENA-78 & GCSF & GM-CSF & GRO & GRO-a & $1-309$ & IL-1a & IL-1 $1 \beta$ \\
\hline $11-2$ & $11-3$ & II-4 & $11-5$ & $\| 1-6$ & 1117 & $11-8$ & II-10 & $\|-12$ & $\| 113$ & $\| 1-15$ & IFN-g \\
\hline $11-2$ & $11-3$ & II-4 & $11-5$ & $\| 1-6$ & $111-7$ & $11-8$ & II-10 & $\| 1 \mid-12$ & $\| 11-13$ & $\| 1-15$ & IFN-g \\
\hline MCP-1 & MCP-2 & MCP-3 & MCSF & $M C D$ & MIG & MIP-1d & RANTES & SCF & $\begin{array}{l}\text { SDF- } \\
\text { 1TA }\end{array}$ & $\mathrm{RC}$ & $\begin{array}{c}\text { TGF- } \\
\beta 1\end{array}$ \\
\hline MCP-1 & MCP-2 & MCP-3 & MCSF & MCD & MIG & MIP-1d & RANTES & SCF & $\begin{array}{l}\text { SDF- } \\
\text { 1TA }\end{array}$ & $\mathrm{RC}$ & $\begin{array}{c}\text { TGF- } \\
\beta 1\end{array}$ \\
\hline TNF- $\alpha$ & TNF- $\beta$ & EGF & IGF-1 & Angogenin & OncostatinM & Thrombopoietin & VEGF & $\begin{array}{c}\text { PDGF- } \\
\text { BB }\end{array}$ & Leptin & - & + \\
\hline TNF- $\alpha$ & TNF- $\beta$ & EGF & IGF-1 & Angogenin & OncostatinM & Thrombopoietin & VEGF & $\begin{array}{c}\text { PDGF- } \\
\text { BB }\end{array}$ & Leptin & - & + \\
\hline
\end{tabular}

Figure 3. Cytokine assay of WF. The dot blot assay was used to analyze the presence of different cytokines in WF. According to the manufacturer, a table was used to assign the different dots to cytokines. Various types of cytokines responsible for pro- and anti-inflammation, chemotaxis, proliferation and angiogenesis were present in WF. WF, wound fluid; IL, interleukin; MCP, monocyte chemoattractant protein; TNF, tumor necrosis factor; EGF, epidermal growth factor; MCSF, macrophage colony-stimulating factor; IGF-1, insulin-like growth factor 1; ENA-78, epithelial-derived neutrophil-activating protein 78; MCD, DDHDHD; GCSF, granulocyte colony stimulating factor; MIG, monokine induced by $\gamma$-interferon; GM-CSF, granulocyte-macrophage colony-stimulating factor; MIP, macrophage inflammatory protein; GRO, growth related oncogene; RANTES, regulated on activation normal t expressed and secreted; VEGF, vascular endothelial growth factor; SCF, stem cell factor; PDGF, platelet-derived growth factor; I-309, chemokine (C-C motif) ligand 1; SDF, stromal cell-derived factor; TARC, thymus- and activation-regulated chemokine; IFN, interferon; TGF, transforming growth factor.

at $4^{\circ} \mathrm{C}$. Subsequently, the membrane was washed and incubated with a species-specific secondary antibody (1:10,000; anti-rabbit immunoglobulin G; HRP-linked antibody, Cell Signaling Technology, Inc.; cat. no. 7074) for $1 \mathrm{~h}$ at room temperature to visualize the specific bindings. Protein expression was detected with an enhanced chemiluminescence system (GE Healthcare), according to the manufacturer's protocol. Jurkat cells (STAT3 control extracts; Cell Signaling Technology, Inc.; cat. no. 9133) were used as a positive control. $\alpha$-tubulin (1:2,000; Sigma-Aldrich; Merck KGaA; cat. no. T5168) was used as control. The DNA-ladder was purchased from Thermo Fisher Scientific, Inc. (cat. no. 26616).

Statistical analysis. All data were transferred to standard spreadsheets and analyzed using GraphPad Prism 6.0 (GraphPad Software, Inc., La Jolla, CA, USA). First, whether the distribution was Gaussian was analyzed. In the case of Gaussian distribution, unpaired Student's t-test was used; otherwise, the Kruskal-Wallis test was performed. $\mathrm{P}<0.05$ was considered to indicate a statistically significant difference.

\section{Results}

Culture of human carcinoma cell lines FaDu and HLaC 87 with WF. The cultivation of FaDu and HLaC78 with WF was possible. The cancer cells were cultivated with WF at different concentrations. WF at a concentration of $40 \%$ induced the highest proliferation in $\mathrm{FaDu}$ and HLaC78. Higher and lower concentrations exhibited reduced cell proliferation (data not shown). Therefore, further experiments were conducted with $40 \%$ WF. Cancer cell proliferation was confirmed using Ki-67 staining, as the expression of $\mathrm{Ki}-67$ is associated with cell division (24). Ki-67 staining revealed an enhanced number of $\mathrm{Ki}-67$ positive cells cultured with WF compared with RPMI-EM (Fig. 1). Microscopy also revealed vital cells in a monolayer as well as in spheroid configuration (Fig. 2).

Cytokine analysis of WF. The dot blot assay demonstrated that WF is comprised of a variety of different cytokines and growth factors. A table was used in order to assign the different dots to corresponding cytokines (Fig. 3). 


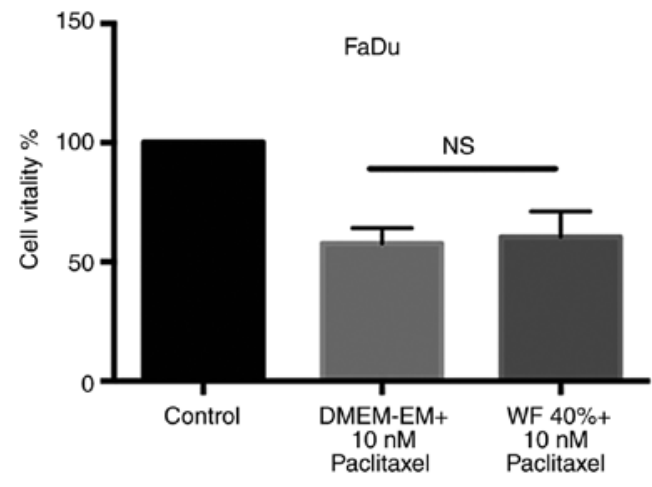

Figure 4. Evaluation of chemoresistance. FaDu cells were cultivated with WF and treated with $10 \mathrm{nM}$ paclitaxel for $24 \mathrm{~h}$. In order to identify differences in cell viability, an MTT assay was performed. This test revealed no significant differences in cell viability following paclitaxel treatment between the cultivation of $\mathrm{FaDu}$ with $40 \%$ WF compared with the control group. WF, wound fluid.

Certain cytokines are responsible for inflammation, e.g., tumor necrosis factor- $\alpha$ and $-\beta$. IL- 6 showed the highest density. Several anti-inflammatory cytokines were represented as well. These cytokines are IL-6, IL-10, IL-13 and transforming growth factor- $\beta$. Factors that induce chemotaxis (25), such as monocyte chemotactic protein (MCP)-1, MCP-2, MCP-3 and IL-8, and factors responsible for angiogenesis such as vascular endothelial growth factor, angiogenin, insulin-like growth factor-1, IL-7, growth-regulated oncogene (GRO), GRO- $\alpha$ and platelet-derived growth factor-BB wee also identified (Fig. 3).

Analysis of chemoresistance. $\mathrm{FaDu}$ and $\mathrm{HLaC} 78$ exhibited enhanced proliferation following cultivation with $40 \%$ WF compared with RPMI-EM. Due to the high number of cytokines and growth factors, the investigation of a resistance induction toward chemotherapeutic substances seemed worthwhile. Therefore, FaDu were cultivated with WF for $24 \mathrm{~h}$. After $24 \mathrm{~h}$, the cells were treated with $10 \mathrm{nM}$ paclitaxel. Previously, the $\mathrm{IC}_{50}(10 \mathrm{nM})$ of paclitaxel was investigated in FaDu (data not shown). The MTT assay revealed no significant differences between WF compared with control after paclitaxel treatment (Fig. 4).

Three-dimensional invasion assay. A possible alteration in the cell invasion activity was investigated using the three-dimensional invasion assay. RPMI-EM served as a control. To determine the migration area, spheroids were imaged directly after being transferred (Fig. 5A and B). In this condition, cells were able to spread out from the spheroids. After $24 \mathrm{~h}$, the cells were photographed again (Fig. 5C and D). WF induced an enhancement in cell motility. The invasion area of cells cultivated with WF was significantly higher compared with the control (Fig. 5E).

Analysis of STAT 3 activation via western blotting. The highest IL-6 signal was the observed in the WF. In order to investigate the activation of STAT3 by WF, a western blot analysis was performed. The western blotting revealed an enhanced phosphorylation of STAT3 in FaDu and HLaC78 following cultivation with WF compared with cultivation with RPMI-EM (Fig. 6). $\alpha$-tubulin was used as control.

\section{Discussion}

Wound healing begins directly after surgery with a modification of the microenvironment via a well-orchestrated interaction between cells, cytokines and growth factors. The process of normal wound healing is dynamic and divided into 4 overlapping phases: Hemostasis, inflammation, proliferation, and remodeling $(26,27)$. The first phase is activated by the endothelial vasoconstriction and clotting cascade. Furthermore, the secretion of pro-inflammatory cytokines and growth factors is induced (28). The inflammatory phase starts immediately, and the migration of cells such as neutrophil granulocytes, monocytes and MSCs is induced $(28,29)$. This is followed by the proliferation phase and the remodeling phase.

Notably, growth factors involved in wound healing can also promote cancer progression and metastasis. Platelet-derived growth factor (PDGF), for example, has an important role in each stage of wound healing (30). Solid cancers express PDGF-receptors, and the stimulation of these receptors may promote carcinogenesis (31). In cases of incomplete tumor-removal during surgery, PDFG potentially comes into contact with non-resected cancer cells, which may lead to the enhancement of cancer cell proliferation (32).

Additionally, GRO has an important role in wound healing by modulating cell migration and angiogenesis as well. In particular, GRO- $\alpha$ seems to promote cancer proliferation, angiogenesis and metastasis $(33,34)$. The dot blot assay revealed that wound fluid (WF) contains several factors that have mitogenic effects on cancer cells. However, it revealed the presence of granulocyte-macrophage colony-stimulating factor (GM-CSF) as well. GM-CSF tends to induce apoptosis and drug sensitization in cancer cells. A previous study demonstrated that GM-CSF induced drug sensitization in breast cancer cells (35). Increasing GM-CSF in the cancer milieu may be a suitable therapeutic regime in cancer treatment.

One of the most important cytokines identified in WF is IL-6. IL-6 is a pleiotrophic cytokine and has an important role in inflammation, immune response hematopoesis and oncogenesis (36). There is an association between inflammatory diseases, e.g. Crohn's disease and malignant neoplasia, and particularly cancer of the head and neck, and high levels of IL-6 $(37,38)$. The signaling cascades induced by IL- 6 depend on targeted cell receptors. One of the most important signals activated by IL-6 is the janus kinase/STAT pathway. STAT proteins are involved in several signaling pathways. There are 7 different STAT family members (STAT1, STAT2, STAT3, STAT4, STAT5a, STAT5b, and STAT6) (39). IL-6 is the most potent activator of STAT3 (40). As WF contains IL-6 in high concentrations, it seemed worthwhile to investigate whether WF induces enhanced activation of STAT3 in cancer cells. The western blot assay revealed a strong activation of STAT3 by WF compared with DMEM-EM. Several other factors such as IL-10, epidermal growth factor (EGF) and PDGF are also potential activators of STAT3 (41-43). WF contains a variety of different growth factors for the activation of STAT3. There may be synergistic effects between these factors with respect to the induction of STAT3 activation, which in turn leads to an enhanced proliferation of cancer cells.

In the present study, the cancer cells exhibited enhanced motility following cultivation with WF. The reason for this enhancement may be the presence of chemokines such as 
A
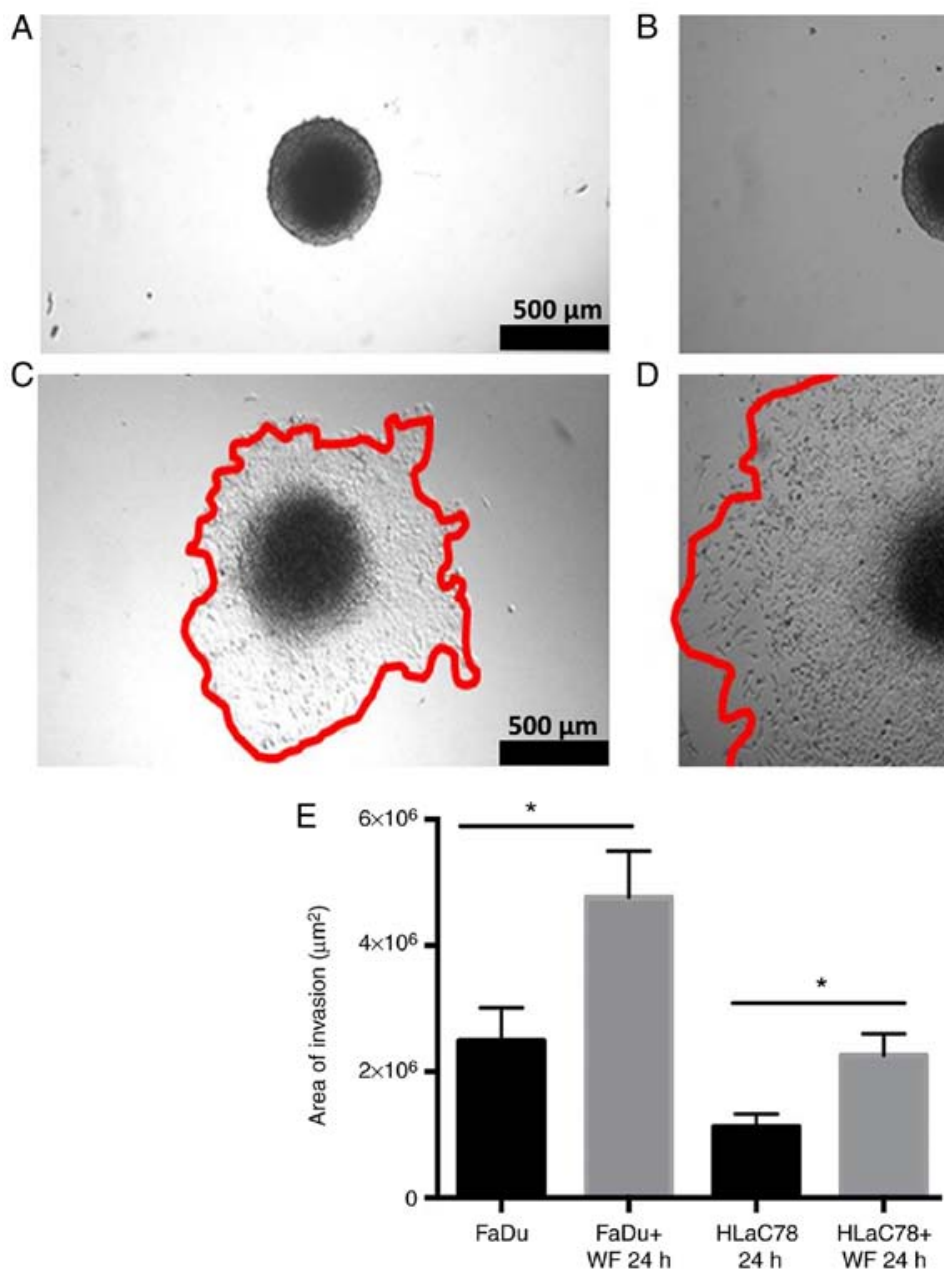

B

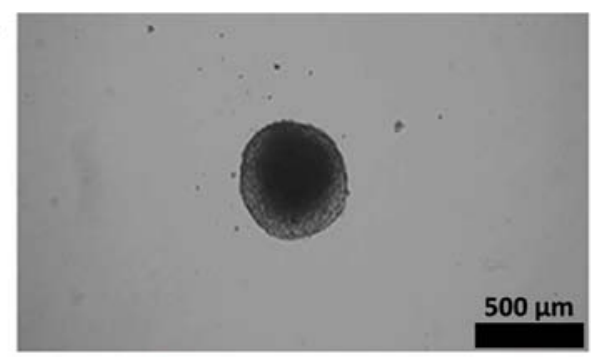

D

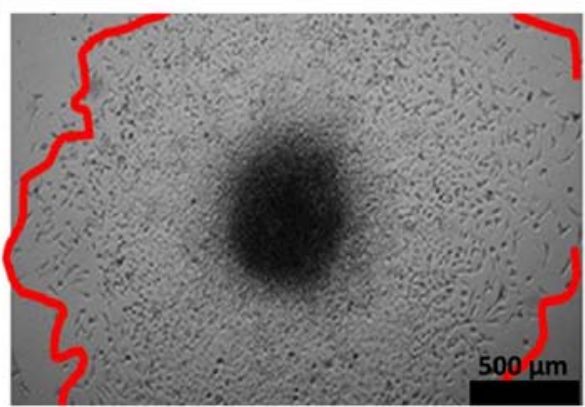

Figure 5. Cancer cell motility. Spheroids made of cancer cell lines were cultivated in (A) RPMI-EM and (B) 40\% WF. Then, they were transferred to well plates without coating in an adherent condition. After $24 \mathrm{~h}$, the migration area of (C) Fadu cultivated in RPMI-EM and (D) Fadu cultivated in $40 \%$ WF was measured using ImageJ software. (E) The migration capability of FaDu and HLaC78 was enhanced significantly after cultivation with $40 \%$ WF compared with cultivation with RPMI-EM. RPMI-EM, RPMI-expansion medium; WF, wound fluid.
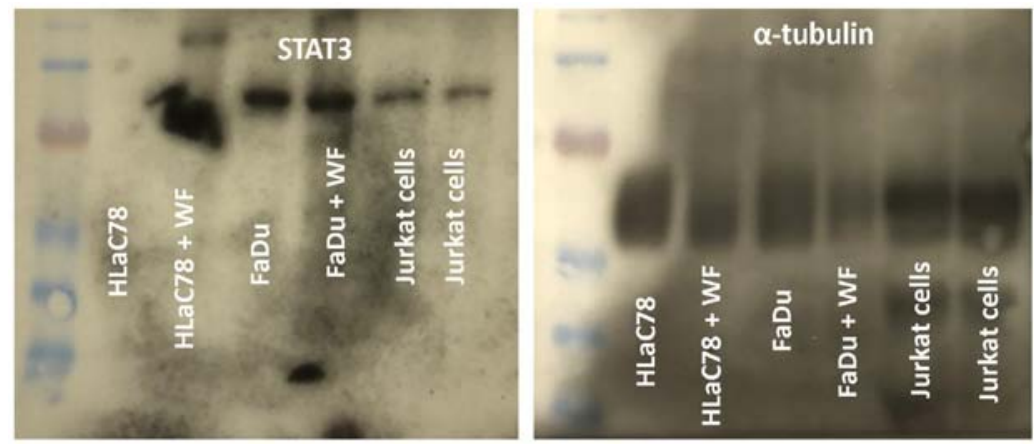

Figure 6. STAT3 expression following WF treatment. The expression levels of STAT3 were examined by western blot analysis in FaDu and HLaC78 treated with WF. The western blotting revealed the expression of STAT3 in FaDu and HLaC78 after cultivation in RPMI-EM and in WF. The expression STAT3 was enhanced in cells cultivated with WF. $\alpha$-tubulin was used as a loading control. STAT3, signal transducer and activator of transcription factor 3; WF, wound fluid.

chemokine (C-C motif) ligand 5 (CCL5) in WF. Chemokines are produced and secreted by the majority of cell types and induce cell migration and various physiological and pathological processes (44). A variety of chemokines are produced during wound healing. In an experiment conducted by Karnoub et al, breast cancer cell motility was enhanced and promoted via secretion of CCL5 from MSC. By adding anti-CCL5, the enhancement of cell motility was counteracted (45). The dot blot assay revealed a strong secretion of CCL5. The contact between residual cancer cells and CCL5 may support cancer cell motility and metastasis. Besides the cytokines and growth factors, lipid acids serve an important role in cancer progression. Surgery may result in microenvironmental stress due to acidosis. The reason for acidosis after surgery are hypovolemia, hypoperfusion and lactic acidosis (46). According to Corbet and Feron (35) 
and Menard et al $(47,48)$, acidosis and hypoxia result from an accumulation of lipoproteins. This is associated with increased spheroid-formation capacity in vitro and enhanced metastatic potential of cancer cells in vivo.

Additionally, other groups have conducted the cultivation of breast cancer cells and WF as well. Wang et al (49) recently demonstrated an enhanced proliferation and migration capacity of breast cancer cells following cultivation with WF. They revealed the presence of several cytokines and growth factors. However, the evaluation of signaling cascades was not conducted. Licitra et al (50) previously investigated the stimulation of EGF receptor (EGFR)-positive residual cancer cells after surgery in the head and neck cancer. They demonstrated an enhanced cell proliferation in EGFR-positive cancer cells, which was inhibited by adding anti-EGFR reagents. The present study demonstrated an enhanced secretion of IL-6 in the WF. The activation of STAT3 via IL-6 may be one of the main reasons for the enhancement of cell proliferation.

The interval between surgery and postoperative radiation therapy is usually 4-6 weeks. During this period, residual cancer cells may recover and form novel tumor manifestations and early metastases. The delayed adjuvant therapy may not target these metastatic cells, which attenuates their survival prognosis significantly. Most cancer cells in the head and neck express epidermal EGFR (51). The EGFR pathway modulates cancer proliferation and metastasis and cancer survival. Sano et al (52) previously postulated that the reason for local-regional failure of oral squamous cell carcinoma may be due to the activation of the EGFR pathway in residual cancer cells during wound healing. Hence, the administration of an anti-EGFR monoclonal antibody such as cetuximab may be valuable. Other monoclonal antibodies such as bevacizumab may result in the inhibition of early vasculogenesis. However, bevacizumab is also associated with multiple complications involved in wound healing and wound infection (53), which may delay the administration of planned adjuvant therapy and counteract the survival prognosis.

In conclusion, enhanced cancer cell proliferation after cultivation with WF was demonstrated in the present study; this was achieved via activation of the STAT3 signaling pathway. Furthermore, WF supported cancer cell motility. However, enhanced resistance to paclitaxel, was not observed. Overall, the present findings emphasize the importance of WF in cancer cell proliferation and motility during wound healing. Future studies should focus on the inhibition of mitogenic factors after cancer surgery in order to prevent early metastasis and cancer recurrence.

\section{Acknowledgements}

Not applicable.

\section{Funding}

No funding was received.

\section{Availability of data and materials}

The datasets analysed during the present study are available from the corresponding author upon reasonable request.

\section{Authors' contributions}

AS and SH designed and conceived the study. AS, RE, SH, TM, $\mathrm{PI}$ and MB performed the experiments. The interpretation of the data was made by AS, SH and TG. RH and NK contributed to the writing of the manuscript and were involved in data interpretation. TG, AS and RE collected the samples. All authors read and approved the manuscript and agree to be accountable for all aspects of the research in ensuring that the accuracy or integrity of any part of the work are appropriately investigated and resolved.

\section{Ethics approval and consent to participate}

Informed consent was provided by all patients. The study was approved by the Ethics Committee of the Medical Faculty of the University of Wuerzburg (Würzburg, Germany).

\section{Patient consent for publication}

Not applicable.

\section{Competing interests}

The authors declare that they have no competing interests.

\section{References}

1. Siegel RL, Miller KD, Fedewa SA, Ahnen DJ, Meester RGS, Barzi A and Jemal A: Colorectal cancer statistics, 2017. CA Cancer J Clin 67: 177-193, 2017.

2. Wynn TA and Vannella KM: Macrophages in tissue repair, regeneration, and fibrosis. Immunity 44: 450-462, 2016.

3. Wynn TA: Cellular and molecular mechanisms of fibrosis J Pathol 214: 199-210, 2008.

4. Valeta-Magara A, Hatami R, Axelrod D, Roses DF, Guth A Formenti SC and Schneider RJ: Pro-oncogenic cytokines and growth factors are differentially expressed in the post-surgical wound fluid from malignant compared to benign breast lesions. SpringerPlus 4: 483, 2015.

5. Cutting KF: Wound exudate: Composition and functions. Br J Community Nurs 8 (Suppl 9): S4-S9, 2003.

6. Abramovitch R, Marikovsky M, Meir G and Neeman M: Stimulation of tumour growth by wound-derived growth factors. Br J Cancer 79: 1392-1398, 1999.

7. Scherzed A, Hackenberg S, Froelich K, Radeloff A, Technau A, Kessler M, Hagen R, Rak K, Koehler C and Kleinsasser N: The effect of wound fluid on adipose-derived stem cells in vitro: A study in human cell materials. Tissue Eng Part C Methods 17: 809-817, 2011.

8. Zhang Y, Ma Q, Liu T, Guan G, Zhang K, Chen J, Jia N, Yan S, Chen G, Liu S, et al: Interleukin-6 suppression reduces tumour self-seeding by circulating tumour cells in a human osteosarcoma nude mouse model. Oncotarget 7: 446-458, 2016.

9. Ara T, Song L, Shimada H, Keshelava N, Russell HV, Metelitsa LS, Groshen SG, Seeger RC and DeClerck YA: Interleukin- 6 in the bone marrow microenvironment promotes the growth and survival of neuroblastoma cells. Cancer Res 69: 329-337, 2009

10. Ogata A, Chauhan D, Teoh G, Treon SP, Urashima M, Schlossman RL and Anderson KC: IL-6 triggers cell growth via the Ras-dependent mitogen-activated protein kinase cascade. J Immunol 159: 2212-2221, 1997.

11. Ataie-Kachoie P, Pourgholami MH and Morris DL: Inhibition of the IL-6 signaling pathway: A strategy to combat chronic inflammatory diseases and cancer. Cytokine Growth Factor Rev 24: 163-173, 2013.

12. Suchi K, Fujiwara H, Okamura S, Okamura H, Umehara S, Todo M, Furutani A, Yoneda M, Shiozaki A, Kubota T, et al: Overexpression of Interleukin-6 suppresses cisplatin-induced cytotoxicity in esophageal squamous cell carcinoma cells. Anticancer Res 31: 67-75, 2011. 
13. Sierra A: Metastases and their microenvironments: Linking pathogenesis and therapy. Drug Resist Updat 8: 247-257, 2005.

14. Abroun S, Saki N, Ahmadvand M, Asghari F, Salari F and Rahim F: STATs: An old otory, vet $\mu$ esmerizing. Cell J 17: 395-411, 2015.

15. Klemm JD, Schreiber SL and Crabtree GR: Dimerization as a regulatory mechanism in signal transduction. Annu Rev Immunol 16: 569-592, 1998.

16. Banerjee $\mathrm{K}$ and Resat $\mathrm{H}$ : Constitutive activation of STAT3 in breast cancer cells: A review. Int J Cancer 138: 2570-2578, 2016

17. Berishaj M, Gao SP, Ahmed S, Leslie K, Al-Ahmadie H, Gerald WL, Bornmann W and Bromberg JF: Stat3 is tyrosine-phosphorylated through the interleukin-6/glycoprotein $130 /$ janus kinase pathway in breast cancer. Breast Cancer Res 9: R32, 2007.

18. Rangan SR: A new human cell line (FaDu) from a hypopharyngeal carcinoma. Cancer 29: 117-121, 1972.

19. Zenner HP, Lehner W and Herrmann IF: Establishment of carcinoma cell lines from larynx and submandibular gland. Arch Otorhinolaryngol 225: 269-277, 1979.

20. Mosmann T: Rapid colorimetric assay for cellular growth and survival: Application to proliferation and cytotoxicity assays. J Immunol Methods 65: 55-63, 1983.

21. Scherzed A, Hackenberg S, Froelich K, Kessler M, Koehler C, Hagen R, Radeloff A, Friehs G and Kleinsasser N: BMSC enhance the survival of paclitaxel treated squamous cell carcinoma cells in vitro. Cancer Biol Ther 11: 349-357, 2011.

22. Scherzad A, Steber M, Gehrke T, Rak K, Froelich K, Schendzielorz P, Hagen R, Kleinsasser N and Hackenberg S: Human mesenchymal stem cells enhance cancer cell proliferation via IL-6 secretion and activation of ERK1/2. Int J Oncol 47: 391-397, 2015

23. Lowry OH, Rosebrough NJ, Farr AL and Randall RJ: Protein measurement with the Folin phenol reagent. J Biol Chem 193: 265-275, 1951

24. Scholzen T and Gerdes J: The Ki-67 protein: From the known and the unknown. J Cell Physiol 182: 311-322, 2000.

25. Loetscher P, Seitz M, Clark-Lewis I, Baggiolini M and Moser B: Monocyte chemotactic protein MCP-1, MCP-2, and MCP-3 are major attractants for human $\mathrm{CD} 4^{+}$and $\mathrm{CD} 8^{+} \mathrm{T}$ lymphocytes. FASEB J 8: 1055-1060, 1994

26. Gonzalez AC, Costa TF, Andrade ZA and Medrado AR: Wound healing - A literature review. An Bras Dermatol 91: 614-620, 2016.

27. Guo S and Dipietro LA: Factors affecting wound healing. J Dent Res 89: 219-229, 2010.

28. Ho J, Walsh C, Yue D, Dardik A and Cheema U: Current advancements and strategies in tissue engineering for wound healing: A comprehensive review. Adv Wound Care 6: 191-209, 2017.

29. Lee DE, Ayoub N and Agrawal DK: Mesenchymal stem cells and cutaneous wound healing: Novel methods to increase cell delivery and therapeutic efficacy. Stem Cell Res Ther 7: 37, 2016

30. Barrientos S, Brem H, Stojadinovic O and Tomic-Canic M: Clinical application of growth factors and cytokines in wound healing. Wound Repair Regen 22: 569-578, 2014.

31. Heldin $\mathrm{CH}$ : Targeting the PDGF signaling pathway in tumor treatment. Cell Commun Signal 11: 97, 2013.

32. Alieva M, van Rheenen J and Broekman ML: Potential impact of invasive surgical procedures on primary tumor growth and metastasis. Clin Exp Metastasis 35: 319-331, 2018

33. Wang B, Hendricks DT, Wamunyokoli F and Parker MI: A growth-related oncogene/CXC chemokine receptor 2 autocrine loop contributes to cellular proliferation in esophageal cancer. Cancer Res 66: 3071-3077, 2006

34. Lian S, Zhai X, Wang X, Zhu H, Zhang S, Wang W, Wang Z and Huang J: Elevated expression of growth-regulated oncogene-alpha in tumor and stromal cells predicts unfavorable prognosis in pancreatic cancer. Medicine 95: e4328, 2016.

35. Chaubey $\mathrm{N}$ and Ghosh SS: Overexpression of granulocyte macrophage colony stimulating factor in breast cancer cells leads towards drug sensitization. Appl Biochem Biotechnol 175: 1948-1959, 2015.
36. Mitsuyama K, Sata $M$ and Rose-John S: Interleukin-6 trans-signaling in inflammatory bowel disease. Cytokine Growth Factor Rev 17: 451-461, 2006.

37. Gallo O, Gori AM, Attanasio M, Martini F, Paola G, Storchi OF and Abbate R: Acute-phase proteins and interleukin 6 serum level in head and neck cancer. Arch Otolaryngol Head Neck Surg 118: 1366-1367, 1992.

38. Chen Z, Malhotra PS, Thomas GR, Ondrey FG, Duffey DC, Smith CW, Enamorado I, Yeh NT, Kroog GS, Rudy S, et al: Expression of proinflammatory and proangiogenic cytokines in patients with head and neck cancer. Clin Cancer Res 5: 1369-1379, 1999.

39. Ihle JN: The stat family in cytokine signaling. Curr Opin Cell Biol 13: 211-217, 2001.

40. Heinrich PC, Behrmann I, Haan S, Hermanns HM, Muller-Newen G and Schaper F: Principles of interleukin (IL)-6-type cytokine signalling and its regulation. Biochem J 374: 1-20, 2003.

41. Wang Y, van Boxel-Dezaire AH, Cheon H, Yang J and Stark GR: STAT3 activation in response to IL-6 is prolonged by the binding of IL-6 receptor to EGF receptor. Proc Natl Acad Sci USA 110: 16975-16980, 2013.

42. Yan JF, Huang WJ, Zhao JF, Fu HY, Zhang GY, Huang XJ and Lv BD: The platelet-derived growth factor receptor/STAT3 signaling pathway regulates the phenotypic transition of corpus cavernosum smooth muscle in rats. PLoS One 12: e0172191, 2017.

43. Simon AR, Takahashi S, Severgnini M, Fanburg BL and Cochran BH: Role of the JAK-STAT pathway in PDGF-stimulated proliferation of human airway smooth muscle cells. Am J Physiol Lung Cell Mol Physiol 282: L1296-L1304, 2002.

44. Ishida Y, Kimura A, Kuninaka Y, Inui M, Matsushima K, Mukaida N and Kondo T: Pivotal role of the CCL5/CCR5 interaction for recruitment of endothelial progenitor cells in mouse wound healing. J Clin Invest 122: 711-721, 2012.

45. Karnoub AE, Dash AB, Vo AP, Sullivan A, Brooks MW, Bell GW, Richardson AL, Polyak K, Tubo R and Weinberg RA: Mesenchymal stem cells within tumour stroma promote breast cancer metastasis. Nature 449: 557-563, 2007.

46. Waters JH, Miller LR, Clack S and Kim JV: Cause of metabolic acidosis in prolonged surgery. Crit Care Med 27: 2142-2146, 1999.

47. Corbet $\mathrm{C}$ and Feron O: Emerging roles of lipid metabolism in cancer progression. Curr Opin Clin Nutr Metab Care 20: 254-260, 2017.

48. Menard JA, Christianson HC, Kucharzewska P, BourseauGuilmain E, Svensson KJ, Lindqvist E, Indira Chandran V, Kjellén L, Welinder C, Bengzon J, et al: Metastasis stimulation by hypoxia and acidosis-induced extracellular lipid uptake is mediated by proteoglycan-dependent endocytosis. Cancer Res 76: 4828-4840, 2016.

49. Wang D, Hu K, Gao N, Zhang H, Jiang Y, Liu C, Wang S and Zhao Z: High throughput screening of cytokines, chemokines and matrix metalloproteinases in wound fluid induced by mammary surgery. Oncotarget 6: 29296-29310, 2015.

50. Licitra L, Perrone F, Tamborini E, Bertola L, Ghirelli C, Negri T, Orsenigo M, Filipazzi P, Pastore E, Pompilio M, et al: Role of EGFR family receptors in proliferation of squamous carcinoma cells induced by wound healing fluids of head and neck cancer patients. Ann Oncol 22: 1886-1893, 2011.

51. Zimmermann M, Zouhair A, Azria D and Ozsahin M: The epidermal growth factor receptor (EGFR) in head and neck cancer: Its role and treatment implications. Radiat Oncol 1: 11, 2006.

52. Sano D, Gule MK, Rosenthal DI, Bell D, Yates J, El-Naggar AK and Myers JN: Early postoperative epidermal growth factor receptor inhibition: Safety and effectiveness in inhibiting microscopic residual of oral squamous cell carcinoma in vivo. Head Neck 35: 321-328, 2013.

53. Gordon CR, Rojavin Y, Patel M, Zins JE, Grana G, Kann B, Simons R and Atabek U: A review on bevacizumab and surgical wound healing: An important warning to all surgeons. Ann Plastic Surg 62: 707-709, 2009. 